\title{
Facebook Campaigning: Political Presentations and the Electronic Word-of-Mouth based on a Functional Approach
}

\author{
Chi Ying Chen ${ }^{1}$, Shao Liang Chang ${ }^{2}$ \\ ${ }^{1}$ Information Communication, Asia University \\ ${ }^{2}$ Business Administration, Asia University
}

\begin{abstract}
This research utilized a functional approach of campaign communication discourse and political visual images to analyze the political presentations by textual and visual information on Facebook and the influence on electronic word-of-mouth by likes and shares. Results revealed that candidates employ a safe strategies. They emphasize on policy more than character and on acclaiming more than attacking and defending. They are inclined to apply gender stereotype resistance because the female candidate tends to present herself in a masculine and reasonable way by utilizing more argumentative images for character issues. The male candidate tends to show himself in a feminine and soft way by employing more emotional visual symbols. The female candidate messages achieve the largest number of 'like' and 'share'.
\end{abstract}

Keywords: Political Presentation, Facebook Campaigning, Functional Approach, Social Media

\section{INTRODUCTION}

The important role of Facebook (FB) in politics was first recognized in the 2008 US presidential election. Ever since then political communication via FB has merited scholarly attention, but research on its political implications has been mostly limited to US samples and data. However, FB has recently become extremely popular in Taiwanese campaigning because it has the highest penetration rate in Asia. The emergence of social networking sites FB increases the potential for candidate exposure at no cost with a viable outlet for full control over presenting a message and image directly to the voters [1] . The use of FB by campaigns becomes ubiquitous due to a rapid growth of active members. However, research of the self-presentation strategies on the platform has been rare. The strategy of how political candidates presenting themselves on FB merits scholarly attention because it is superior to any other form of campaign communication like direct mail or official website in empowering a candidate to self-disclose and in enabling two communication partners to feel close. By texts and images presented in a coherent manner, campaigns are able to advance a well-crafted persona of the candidate on FB [2]. Therefore, measures of presentation strategy and the influences are becoming vital to understanding this new political social environment.

This research utilized a functional approach of campaign communication discourse[3] and political visual images [4] to analyze how candidates managed and presented both textual and visual information during the Taiwanese presidential election in 2016. Furthermore, our study sought to determine what makes candidate's strategy of presentation successful on FB.Furthermore, our study sought to determine what makes candidate's strategy of political presentation successful on FB. It was suggested to measure the success of political communications on social media in terms of creating

$\left.{ }^{1}\right]$ V. Gueorguieva, "Voters, MySpace, and YouTube: The impact of alternative communication channels on the 2006 election cycle and beyond," Social Science Computer Review, Vol. 26, No. 3, pp. 288-300, 2008.

$\left.{ }^{2}\right]$ E. Flicker, "Fashionable (dis-)order in politics: Gender, power and the dilemma of the suit," International Journal of Media \& Cultural Politics, Vol. 9, No. 2, pp. 201-219, 2013.

$\left.{ }^{[3}\right]$ W. LBenoit, \&J. Compton, "A functional analysis of 2012 republican primary TV spots," American Behavioral Scientist, Vol. 58, pp. 497-509, 2014.

$\left[{ }^{4}\right]$ D. Schill, "The visual image and the political image: A review of visual communication research in the field of political communication," Review of Communication, Vol. 12, No. 2, pp. 118-142, 2012. 
awareness and engagement[5]. The electronic word-of-mouth (eWOM) intention by the number of "like" and "share" is in accordance with the concept of awareness and engagement. Therefore, we also examined the influence on eWOM by numbers of likes and shares of candidate posts.

\section{LiteratURE REVIEW}

\subsection{Theory}

The functional theory of political discourse claims that candidates maintain their preferability by campaign messages with the three fundamental functions on two topics[6]. In order to accomplish a goal of persuading voters that a candidate was preferable than his or her opponents, the three fundamental functions of campaign discourse are acclaiming, attacking, and defending. Acclaiming portrays a candidate favorably through positive statements that emphasize the candidate's advantages, whereas attacking portrays an opposing candidate unfavorably through negative statements that highlight his or her disadvantages. Defending explicitly responds to a prior attack on the candidat. Topic is another important dimension in political discourse. Campaign discourse focuses on either policy/issues - problems of public domains or proposals to rectify those problems and - or on character/image - the candidates' personalities, competence, and values[7].

Visual symbols play a central role in constructing images for politicians. However, their importance was not noticed. Schill argued that "the visual aspects of political communication remain one of the least studied and the least understood areas, and research focusing on visual symbols in political communication is severely lacking" [4, p. 119]. By reviewing data on how candidates used visuals through what he termed the "image bite", Schill provided a comprehensive overview which assessed political visual communication under ten functions: argument; agenda-setting; dramatization; emotion; image-building; identification; documentation; societal symbol; transportation; and ambiguity.

\subsection{Research Questions}

Five research questions were framed as following:

RQ1: What were the relative emphases on text topics in the candidate's FB pages?

RQ2: What were the relative emphases on text functions in the candidate's FB pages?

RQ3: What were the relative emphases on visual functions in the candidate's FB pages?

RQ4: How were the posts structured by text and image of various functions?

RQ 5: What were the responses by 'like' and 'share' to the posts?

\section{METHOD}

\subsection{Sample}

This study was conducted by a method of quantitative content analysis. All postings in two presidential candidates' FB pages were downloaded starting from two months before the vote in the 2016 Taiwan presidential election. The two candidates in the 2016 Taiwanese presidential election were KMT chair Eric Chu (male) and PPT chair Ing-Wen Tsai (female), both of whom were not incumbent. All FB posts with text and/or visual images, excluding those shared or with just page link, were downloaded. There were 68 posts collected from Tsai's page and 85 posts from Chou's page, and all of them are in a form of combination of text and visual messages.

\subsection{Coding}

[5] Hofmann S, Räckers M, Beverungen D \& Becker J. Old blunders in new media? How local governments communicate with citizens in online social networks. Hawaii International Conference on Systems Sciences, 2013.

[6] W.C. Wen, "FB political communication in Taiwan: 1.0/2.0 messages and election/post-election messages", Chinese Journal of Communication, Vol, 7, No. 1, pp. 19-39, 2014.

[7] Benoit, WL. (2007) Communication in political campaign communications. New York, NY: Peter Lang. 
The coding process was based on the functional approach of campaign communication discourse and political visual images as discussed earlier. The text of each FB post was coded as a function (acclaim, attack, or defense) under a main topic (policy or character), and the imagery was coded as a function of the ten (argument, agenda-setting, dramatization, emotion, image-building, identification, documentation, societal symbol, transportation, and ambiguity).

\section{RESULT}

The first research question asked what the relative emphases on text topics in the candidate's FB pages. The result of Table 1 indicated that both of them emphasized policy over character but the female hold much higher portion of policy text $(85.3 \%)$ than the male did $(56.5 \%)$.

The second research question concerned what the relative emphases on functions in the candidate's FB pages. The result of Table 1 revealed that both candidates stressed the function of acclaiming. They rarely utilized defending, probably because the candidates wanted to avoid giving exposure to their opponent in a personal FB page.

Table1. Statistics of text topics and functions

\begin{tabular}{|l|r|r|r|r|r|}
\hline \multirow{2}{*}{} & \multicolumn{3}{|c|}{ Function } & \multicolumn{2}{c|}{ Topic } \\
\cline { 2 - 6 } & Acclaiming & Attacking & Defending & Policy & \multicolumn{1}{c|}{ Character } \\
\hline Ing-Wen Tsai & $65(97 \%)$ & $1(1.5 \%)$ & $1(1.5 \%)$ & $58(85.3 \%)$ & $10(14.7 \%)$ \\
\hline Eric Chou & $80(94 \%)$ & $5(6 \%)$ & 0 & $48(56.5 \%)$ & $37(43.5 \%)$ \\
\hline Total & $146(95.4 \%)$ & $6(3.9 \%)$ & $1(0.7 \%)$ & $106(69.3 \%)$ & $47(30.7 \%)$ \\
\hline
\end{tabular}

The third research question explored the relative emphases on imagery functions in the candidate's Facebook pages. Table 2 showed visual symbols by two candidates were in a different pattern. Chou's visual images contained a much higher proportion of emotion, image building, and identification than the other functions. Tsai employed various functions overall, but the proportion of emotion is slightly higher.

Table2. Statistics of imagery functions

\begin{tabular}{|c|c|c|c|c|c|c|c|c|c|c|c|}
\hline & $\mathbf{1}$ & $\mathbf{2}$ & $\mathbf{3}$ & $\mathbf{4}$ & $\mathbf{5}$ & $\mathbf{6}$ & $\mathbf{7}$ & $\mathbf{8}$ & $\mathbf{9}$ & $\mathbf{1 0}$ & Total \\
\hline Tsai & 10 & 8 & 6 & 12 & 7 & 10 & 6 & 3 & 4 & 2 & 68 \\
& $14.7 \%$ & $11.8 \%$ & $8.8 \%$ & $17.6 \%$ & $10.3 \%$ & $14.7 \%$ & $8.8 \%$ & $4.4 \%$ & $5.9 \%$ & $2.9 \%$ & $100 \%$ \\
\hline Chou & 4 & 0 & 2 & 27 & 24 & 15 & 3 & 5 & 3 & 2 & 85 \\
& $4.7 \%$ & $0 \%$ & $2.4 \%$ & $31.8 \%$ & $28.2 \%$ & $17.6 \%$ & $3.5 \%$ & $5.9 \%$ & $3.5 \%$ & $2.4 \%$ & $100 \%$ \\
\hline
\end{tabular}

1.Argument; 2.Agenda setting; 3.Dramatizing; 4.Emotion; 5.Image building; 6.Identification; 7.Documentation; 8. Societal symbol; 9. Transportation; 10. Ambiguity

The fourth research question explored how the posts were structured by text and image of various functions. Visual messages of emotion, image building, and identification were mostly combined with both policy and character texts on Chou's page (Table 3). Tsai often presented policy texts with emotional images but mostly presented character texts with argumentative images (Table 4).

Table3. Communication strategy by the male candidate Chou

\begin{tabular}{|c|c|c|c|c|c|c|c|c|c|c|c|}
\hline & $\mathbf{1}$ & $\mathbf{2}$ & $\mathbf{3}$ & $\mathbf{4}$ & $\mathbf{5}$ & $\mathbf{6}$ & $\mathbf{7}$ & $\mathbf{8}$ & $\mathbf{9}$ & $\mathbf{1 0}$ & Total \\
\hline Policy & 4 & 0 & 1 & 14 & 11 & 12 & 1 & 2 & 1 & 2 & 48 \\
& $8.3 \%$ & 0 & $2.1 \%$ & $29.2 \%$ & $22.9 \%$ & $25.0 \%$ & $2.1 \%$ & $4.2 \%$ & $2.1 \%$ & $4.2 \%$ & $100 \%$ \\
\hline Character & 0 & 0 & 1 & 13 & 13 & 3 & 2 & 3 & 2 & 0 & 37 \\
& $0 \%$ & 0 & $2.7 \%$ & $35.1 \%$ & $35.1 \%$ & $8.1 \%$ & $5.4 \%$ & $8.1 \%$ & $5.4 \%$ & $.0 \%$ & $100 . \%$ \\
\hline
\end{tabular}

1.Argument; 2.Agenda setting; 3.Dramatizing; 4.Emotion; 5.Image building; 6.Identification; 7.Documentation; 8. Societal symbol; 9. Transportation; 10. Ambiguity

Table4. Communication strategy by the female candidate Tsai

\begin{tabular}{|c|c|c|c|c|c|c|c|c|c|c|c|}
\hline & $\mathbf{1}$ & $\mathbf{2}$ & $\mathbf{3}$ & $\mathbf{4}$ & $\mathbf{5}$ & $\mathbf{6}$ & $\mathbf{7}$ & $\mathbf{8}$ & $\mathbf{9}$ & $\mathbf{1 0}$ & Total \\
\hline Policy & 4 & 8 & 4 & 12 & 7 & 9 & 6 & 3 & 3 & 2 & 58 \\
& $6.9 \%$ & $13.8 \%$ & $6.9 \%$ & $20.7 \%$ & $12.1 \%$ & $15.5 \%$ & $10.3 \%$ & $5.2 \%$ & $5.2 \%$ & $3.4 \%$ & $100 . \%$ \\
\hline Character & 6 & 0 & 2 & 0 & 0 & 1 & 0 & 0 & 1 & 0 & 10 \\
& $60.0 \%$ & $0 \%$ & $20.0 \%$ & $0 \%$ & $0 \%$ & $10.0 \%$ & $0 \%$ & $0 \%$ & $10.0 \%$ & $0 \%$ & $100 \%$ \\
\hline
\end{tabular}

1.Argument; 2.Agenda setting; 3.Dramatizing; 4.Emotion; 5.Image building; 6.Identification; 7.Documentation; 8.Societal symbol; 9. Transportation; 10. Ambiguity 
The fifth research question examined the influence of political presentations on the eWOM. Both the average like and share earned by Tsai's posts were more than Chou's. More specifically, the post earning the highest like fell into Tsai's page (110,000 likes); that is almost twice the highest number by Chou's post $(57,211$ likes). The post earning the largest share was also one of Tsai's posts $(8,150$ shares); that is more than twice the highest number by Chou's post $(3,264)$. It indicated the communication strategy by the female candidate was more successful and the factors is worth of further studies.

Table5. Statistics of messages earning likes and shares

\begin{tabular}{|l|l|c|c|c|c|c|}
\hline & FB & Post & Average & Max & Min & SD \\
\hline \multirow{2}{*}{ Like } & Tsai & 68 & $28,346.24$ & 110,000 & 8,690 & $21,539.76$ \\
\cline { 2 - 7 } & Chou & 85 & $21,185.76$ & 57,211 & 9,306 & $9,924.39$ \\
\hline \multirow{2}{*}{ Share } & Tsai & 68 & $1,414.19$ & 8,150 & 204 & $1,673.11$ \\
\cline { 2 - 7 } & Chou & 85 & 637.82 & 3,264 & 100 & 512.33 \\
\hline
\end{tabular}

\section{CONCLUSION}

In recent years, politicians have increasingly turned to using FB because it has emerged as the most prominent social media application worldwide. FB offers virtually unlimited space and full control over the structure and design of the messages. Not surprisingly, the use of Facebook by campaigns becomes ubiquitous. Extensive research has been conducted to examine the effects of FB campaigning on the public. Nevertheless, the main limitation of previous research is that insufficient attention has been paid toward the political presentations. Therefore, this research explores the FB campaigning by analyzing how the presidential candidates present themselves and the responses by like and share.

In this research, one hundred and fifty three messages were collected. Sixty-eight posts were collected from the female presidential candidate Tsai's FB and eighty five posts were from the male candidate Chou's FB. We may conclude two important findings based on the results. First, both of them employ a safe presentation strategy. They emphasize on policy more than character and on acclaiming more than attacking and defending because it is believed that voters are more concerned about policy and acclaiming messages are perceived more positive than attacking and defending ones. Second, strategies of gender stereotype resistance were applied in the FB campaigning. Tsai tends to present herself in a masculine and reasonable way by utilizing more argumentative images for character issues, whereas, Chou is inclined to show himself in a feminine and soft way by employing more emotional visual symbols.

This research transcends past studies that mostly focused on either text or photographs. Future study may use content analysis to further explore the factors influencing the response of like and share.

\section{REFERENCES}

[1] V. Gueorguieva, "Voters, MySpace, and YouTube: The impact of alternative communication channels on the 2006 election cycle and beyond," Social Science Computer Review, Vol. 26, No. 3, pp. 288-300, 2008.

[2] E. Flicker, "Fashionable (dis-)order in politics: Gender, power and the dilemma of the suit," International Journal of Media \& Cultural Politics, Vol. 9, No. 2, pp. 201-219, 2013.

[3] W. LBenoit, \&J. Compton, "A functional analysis of 2012 republican primary TV spots," American Behavioral Scientist, Vol. 58, pp. 497-509, 2014.

[4] D. Schill, "The visual image and the political image: A review of visual communication research in the field of political communication," Review of Communication, Vol. 12, No. 2, pp. 118-142, 2012.

[5] Hofmann S, Räckers M, Beverungen D \& Becker J. Old blunders in new media? How local governments communicate with citizens in online social networks. Hawaii International Conference on Systems Sciences, 2013.

[6] W.C. Wen, "FB political communication in Taiwan: 1.0/2.0 messages and election/post-election messages", Chinese Journal of Communication, Vol, 7, No. 1, pp. 19-39, 2014.

[7] Benoit, WL. (2007) Communication in political campaign communications. New York, NY: Peter Lang. 